\title{
Laser-induced methods for obtaining carbon nanomaterials in liquid nitrogen under femtosecond radiation
}

\author{
Kirill S. Khorkov, Valery G. Prokoshev, Sergey M. Arakelian $\bowtie$ \\ Vladimir State University, 87, Gorky St., Vladimir 600000, Russian Federation \\ $\bowtie$ arak@vlsu.ru
}

\begin{abstract}
The paper presents the experimental results of nanostructures formation under the influence of femtosecond laser radiation on carbon samples at liquid nitrogen temperatures. Two femtosecond laser systems were used to study the processes of laser action on highly oriented pyrolytic graphite and glassy carbon samples in liquid nitrogen: titaniumsapphire laser system with wavelength $800 \mathrm{~nm}$, pulse duration $50 \mathrm{fs}$, energy $1 \mathrm{~mJ}$, and repetition frequency of $1 \mathrm{kHz}$; ytterbium laser system with wavelength $1030 \mathrm{~nm}$, pulse duration $280 \mathrm{fs}$, energy $150 \mu \mathrm{J}$, and repetition frequency of $10 \mathrm{kHz}$. Cryostats, including those with the possibility of observing the laser action process, were collected for the experiments. As a result of laser action on the surface of the processed carbon samples, sheets of exfoliated graphene of various sizes and shapes (sheets, tapes, crumpled graphene), as well as nanostructures in the form of nanopeaks, were obtained. The mechanisms of graphene exfoliation under femtosecond laser action in liquid nitrogen, consisting in intercalation and further heating of nitrogen molecules in the interplanar space of graphite, were proposed. The possibilities of further research and development of technologies for graphene formation using laser radiation are presented.
\end{abstract}

Keywords: nanostructures; carbon; graphene; ultrashort laser pulses; liquid nitrogen.

For citation: Khorkov KS, Prokoshev VG, Arakelian SM. Laser-induced methods for obtaining carbon nanomaterials in liquid nitrogen under femtosecond radiation. Journal of Advanced Materials and Technologies. 2021;6(2):101-112. DOI: 10.17277/jamt.2021.02.pp.101-112

\section{Лазерно-индуцированные методы получения углеродных наноматериалов в жидком азоте под действием излучения фемтосекундной длительности}

\author{
К. С. Хорьков, В. Г. Прокошев, С. М. Аракелян ${ }^{\square}$ \\ ФГБОУ ВО «Владимирский государственный университет имени Александра Григорьевича \\ и Николая Григорьевича Столетовыхџ, ул. Горького, 87, Владимир 600000, Российская Федераиия \\ arak@vlsu.ru
}

\begin{abstract}
Аннотация: Представлены результаты экспериментов по формированию наноструктур при воздействии фемтосекундного лазерного излучения на углеродные образцы при температурах жидкого азота. Для исследования процессов лазерного воздействия на образцы высокоориентированного пиролитического графита и стеклоуглерода в жидком азоте использованы две фемтосекундные лазерные системы: титан-сапфировая лазерная система с длиной волны 800 нм, длительностью импульсов 50 фс, энергией 1 мДж, частотой повторения 1 кГц; иттербиевая лазерная система с длиной волны 1030 нм, длительностью импульсов 280 фс, энергией 150 мкДж, частотой повторения 10 кГц. Для проведения экспериментов собраны криостаты, в том числе с возможностью наблюдения процесса воздействия. В результате воздействия лазерного излучения на поверхности обработанных углеродных образцов получены листы отслоенного графена различных размеров и формы (листы, ленты, скомканный графен), а также наноструктуры в виде нанопиков. Предложены механизмы эксфолиации графена при фемтосекундном лазерном воздействии в жидком азоте, заключающиеся в интеркалировании и дальнейшем нагреве молекул азота в межплоскостное пространство графита. Приведены возможности дальнейшего развития исследований и развития технологий формирования графена с помощью лазерного излучения.
\end{abstract}


Ключевые слова: наноструктуры; углерод; графен; ультракороткие лазерные импульсы; жидкий азот.

Для цитирования: Khorkov KS, Prokoshev VG, Arakelian SM. Laser-induced methods for obtaining carbon nanomaterials in liquid nitrogen under femtosecond radiation. Journal of Advanced Materials and Technologies. 2021;6(2):101-112. DOI:10.17277/jamt.2021.02.pp.101-112

\section{Introduction}

At present, one of the promising directions in fundamental and applied science is the study of surface modification of carbon materials under laser radiation. Carbon nanomaterials represent a whole class of materials demanded by modern micro- and nanoelectronics. Immediately after its discovery and presentation to the scientific community, graphene attracted wide attention which led to the appearance of a large number of works devoted to its properties and methods of obtaining. Their results are summarized in a number of review works [1-6], on the basis of which conclusions about the current state of the problem can be drawn.

Due to its electronic structure and chemical composition, graphene is extremely attractive for creating new nanomaterials and using it in nanoelectronic devices [7-10]. Graphene has a number of important chemical and physical characteristics, such as strong mechanical strength, unusually high electrical and thermal conductivity, large specific surface area and capacity $\left(550 \mathrm{~F} \cdot \mathrm{g}^{-1}\right)$, adjustable band gap, manifestation of the quantum Hall effect, extremely high charge carrier mobility, high elasticity, and good electromechanical characteristics [11-13]. Electrons propagate through the two-dimensional structure of graphene and have a linear relationship between momentum and energy, thus behaving like massless Dirac fermions. Hence, it follows that graphene contains a two-dimensional (2D) gas of charged particles with electronic properties described by the Dirac equation, and not by the Schrödinger equation for particles with a certain effective mass.

These features make graphene an extremely versatile promising carbon material for a variety of applications, including high-performance nanocomposites, transparent conductive films, sensors, nanoelectronic devices, and as promising electrode materials for energy storage electrochemical capacitors with high specific power, fast charge-discharge and long life cycle [14, 15].

Realization of the high potential for the applied use of graphene and materials including graphene is possible provided that simple and inexpensive methods for obtaining this functional material with specified characteristics and dimensions are developed. One of the key processes of nano- and microscale surface treatment of materials is femtosecond laser ablation of matter in liquid media. Laser treatment due to its simplicity and versatility makes it possible to structure the surface of materials with low cost, high productivity and repeatability of results, as well as the localization of exposure, which is a fundamental advantage over other methods of material processing [16].

Today, there are many methods of liquid-phase separation of graphene based on the use of surfactants. The main conditions for the effective use of the liquid-phase separation method are the high penetrating ability of liquid molecules into the interlayer space of graphite, the existence of a mechanism for weakening interlayer bonds, and a method for separating layers. Thus, further crystal separation into its constituent monolayers becomes possible.

This work presents an approach which allows eliminating two serious drawbacks of existing implementations of the liquid-phase separation method: the duration of treatment and contamination with residues of surfactants. For graphene exfoliation (detachment of graphite planes), the applied approach uses laser photomechanical effects which manifest themselves more strongly, the shorter the pulse duration of the laser radiation, optimally in the femtosecond range. It is known that rapid laser heating leads to the appearance of strong thermoelastic stresses, as a result of which the front surface of the irradiated sample may spall off in the region of exposure to femtosecond laser radiation $[17,18]$. However, as studies show, in the interaction field of laser radiation and carbon materials [19, 20], including their nanostructuring purposes, some thermal effects accompanying laser action prevent the direct formation of nanostructures with clear boundaries.

Therefore, for the successful use of laser radiation for graphene exfoliation, it is necessary to provide special conditions for the rapid cooling of the laser area. For this purpose, we used a cryostat module (for simplicity, it was open), the role of which was to fix and cool the sample. In addition, when the target is exposed to laser action, a larger temperature gradient is created in the positioning of the medium, which increases thermoelastic stresses. This scheme ensured the production of graphene material of various classes in times that are several orders of magnitude shorter than in other methods of graphene synthesis. 


\section{Materials and Methods}

\subsection{Initial Materials}

Targets made of highly oriented pyrolytic graphite $(\mathrm{HOPG}) \mathrm{HOPG}-1.7-10 \times 10 \times 1-1$ and glassy carbon GC-2000 were used as initial samples for graphene production. HOPG is, in principle, the best material for peeling graphene from a graphite target, since it is formed from high-quality graphite layers that are practically parallel to each other. Glassy carbon, on the other hand, has a rather complex structure, which is a tangle of randomly intertwined carbon ribbons cross-linked with carbon bonds of various multiplicity. It is obvious that glassy carbon cannot be a source of flat graphene sheets. However, for a number of graphene applications, for example, as a material for electrodes of supercapacitors or for reinforcing nanoceramics, it is necessary that it has a complex developed surface.

\subsection{Methods}

During the experiments, two femtosecond laser systems were used: a titanium-sapphire laser system (Avesta-Project, Troitsk, Russia): $\lambda=800 \mathrm{~nm}$, $\tau=50 \mathrm{fs}$, Epulsemax $=1 \mathrm{~mJ}, f=1 \mathrm{kHz}$; an ytterbium laser system TETA-10 (Avesta-Project, Troitsk, Russia): $\lambda=1030 \mathrm{~nm}, f=10 \mathrm{kHz}, \tau=280 \mathrm{fs}$, Epulsemax $=150 \mu \mathrm{J}$, which, together with analytical equipment, make it possible to study the interaction of laser radiation with a wide range of materials along given trajectories and under required conditions. The experimental schemes are shown in Fig. 1. Liquid nitrogen covered the graphite sample with a layer about $5-10 \mathrm{~mm}$ thick. The diameter of the laser radiation spot on the target surface reached $100 \mu \mathrm{m}[21]$.
To carry out the experiments, optical schemes for the action of laser radiation on matter, including the features of specific experiments in various media with controlled parameters, were assembled. Devices for fixing samples identifying areas of laser interaction using optical microscopes and deposition of products of laser action (laser ablation) on a substance in atmospheric air and liquid nitrogen were designed. The use of a high-speed camera in the complex allowed both to follow the process of laser exposure to the sample in real time and to evaluate the quality of the processing performed. The software interface allowed to stop broadcasting the video image at the current frame, as well as to take a snapshot of the current image in order to analyze it [22].

The operation principle of the experimental unit with a double-circuit cryostat is as follows (Fig. 1b). The carbon sample 4 is placed in the cryostat 6 and installed in the chamber 8 connected to the turbomolecular pump 5. Through the liquid nitrogen supply system 7 , the cryostat is filled and the sample is processed with laser radiation. The source of liquid nitrogen is a heat-insulating vessel 11 . The treatment is carried out by laser radiation 9 emitted from the source 1 and directed by means of mirrors 2. The laser radiation is introduced through the transparent windows of the vacuum chamber and cryostat 10 . Elimination of combustion products and liquid nitrogen vapors is carried out through the exhaust system 3. The used liquid nitrogen is discharged into the tank 12 where it is further evaporated.

Upon completion of the laser treatment, the targets were kept in vivo until the liquid nitrogen was completely evaporated. The study of laser action on graphite targets was carried out on the basis of images obtained using a scanning electron microscope (SEM) Quanta 200 3D (FEi Ing., USA)

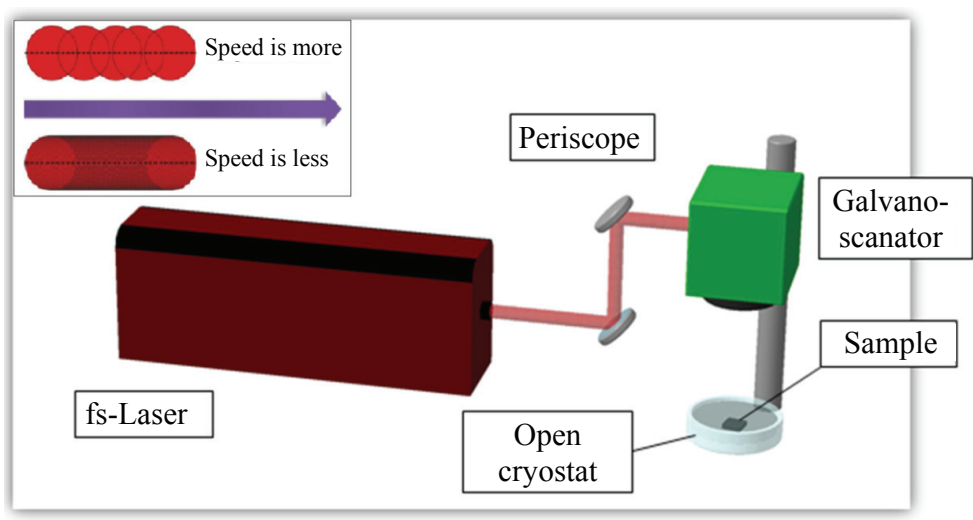

(a)

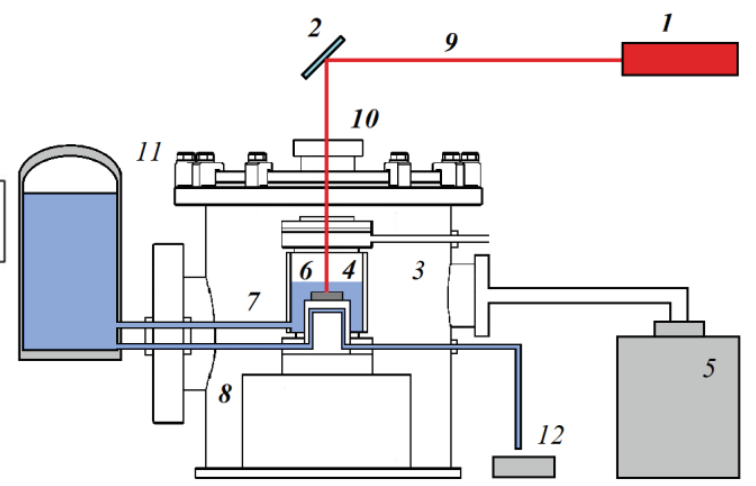

(b)

Fig. 1. Experimental schemes of graphene structures formation: $a$-with an open cryostat; $b-$ with a double-circuit cryostat 
and Raman spectra using a probe nanolaboratory Ntegra Spectra (NT-MDT, Zelenograd, Russian Federation).

The developed method [23] significantly increases the efficiency of the production process for this promising material. It assumes not only a short laser processing time, but also a fundamental exclusion of the purification stage of the resulting graphene from chemicals used in other methods as technological media. The liquid nitrogen used in the considered method evaporates rapidly under natural conditions. The latter factor is especially important, since it provides a higher purity of both the resulting graphene and its production process.

\section{Results and discussion}

When processing HOPG samples in liquid nitrogen using an ytterbium laser system, the velocity of the laser beam on the target surface was from 10 to $100 \mathrm{~cm} \cdot \mathrm{s}^{-1}$. Accordingly, depending on the scanning speed of the beam, each area of the target surface was exposed to femtosecond laser radiation from 1 to 10 pulses. The graphene split off at a laser beam speed of $25 \mathrm{~cm} \cdot \mathrm{s}^{-1}$, when the overlap of laser pulses was $75 \%$. With a larger overlap, a strong destruction of the target surface and, at the same time, the peeled carbon material begins, which is caused by the addition of energy and the development of a laserinduced plume above the affected surface area.

The bulk of the obtained graphene material has linear dimensions of a few micrometers (Fig. 2). As a rule, split-off sheets have numerous folds, but there are also separate sheets with a flat surface (Fig. 2b). Individual graphene structures reaching sizes in the range from 10 to $30 \mu \mathrm{m}$ were registered (Fig. 3). Also, graphene sheets of various shapes were obtained: tapes with a width of up to $50 \mu \mathrm{m}$ and a length of more than $150 \mu \mathrm{m}$ and plates with a characteristic size of more than $150 \mu \mathrm{m}$ [24].

The thickness of the obtained graphene sheets was assessed using a scanning electron microscope along the edge of a relatively flat plate shown in Fig. $2 b$. The registered sheet thickness (taking into account focusing errors) does not exceed $10 \mathrm{~nm}$, which corresponds to multilayer graphene combining about 30 graphite layers.

The analysis of the highly oriented pyrographite surface treated with femtosecond laser radiation showed a strong influence on the results of the uneven intensity distribution over the cross section of the laser beam. In the central part of the focusing spot, packets of graphite layers are torn out (Fig. 4a). These layers are spaced from each other, but cannot be considered as separate graphene structures.

The advantages of the developed method are visible when compared with the closest implementation of the method for producing graphene by liquid-phase graphite exfoliation [25], which proposes to exfoliate graphene in liquid nitrogen when the surface of pyrolytic graphite is exposed to nanosecond laser radiation. The target surface was treated with a stationary laser beam focused into a spot with a diameter of $500 \mu \mathrm{m}$ for $20 \mathrm{~min}$. At the same time, such dimensions of the laser spot on the target did not lead to delamination of graphene sheets with a large surface area. The geometrical characteristics of the obtained graphene are similar to our results with an increase in the area of the irradiated surface, which makes it possible to increase the mass yield of the graphene material.

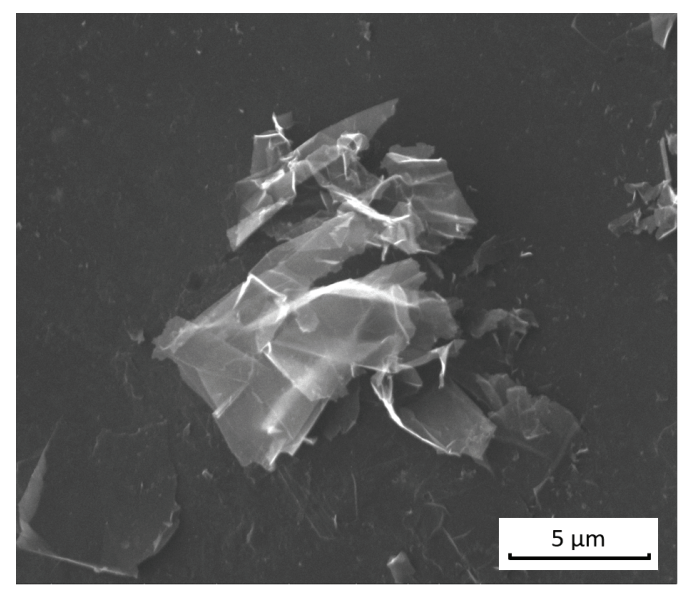

(a)

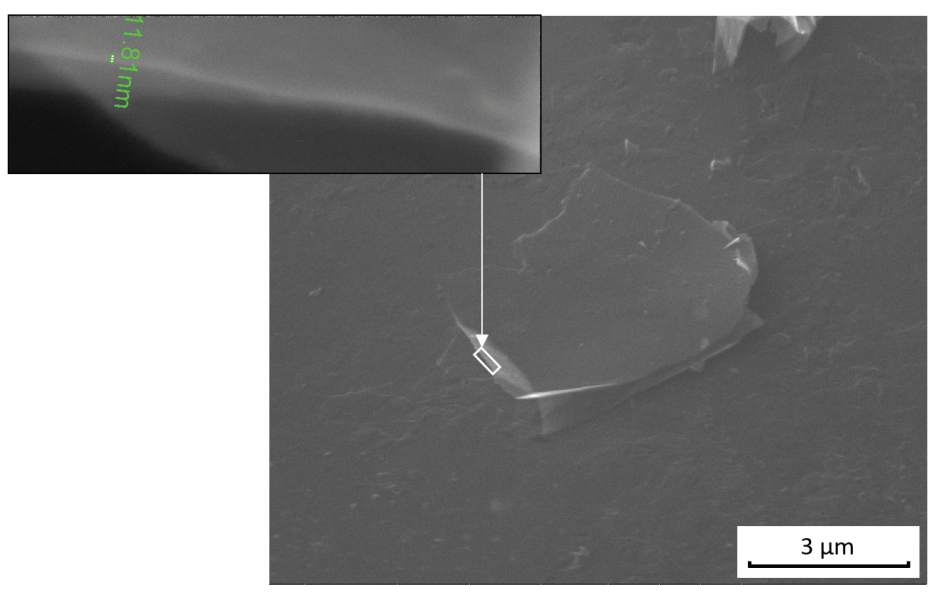

(b)

Fig. 2. SEM images of graphene material:

$a$ - a cluster of graphene sheets; $b$ - a graphene sheet (on the insert - the sheet edge) 


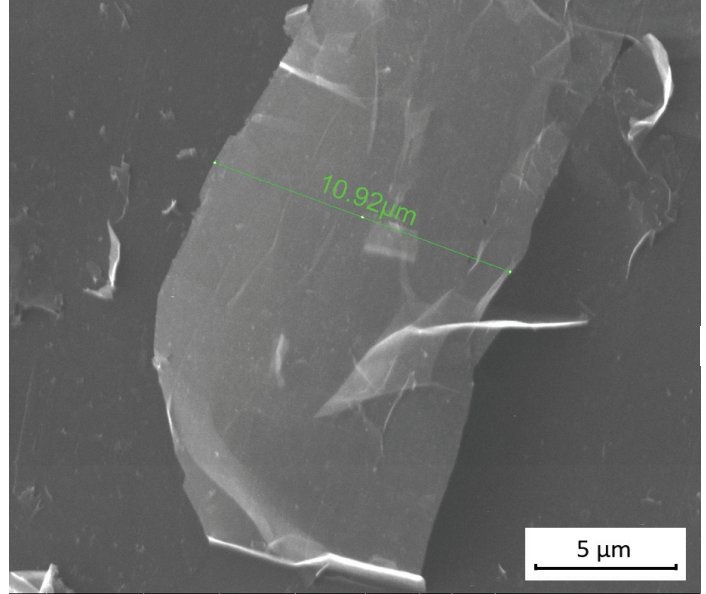

(a)

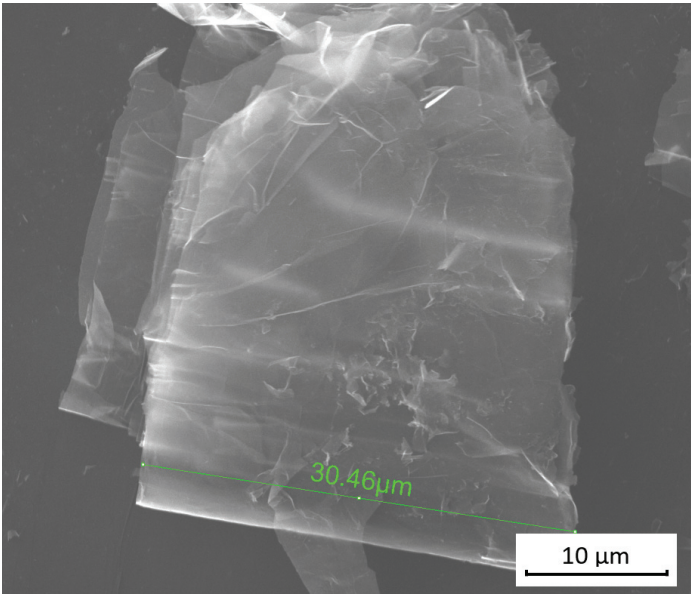

(b)

Fig. 3. SEM images of graphene material with linear dimensions $10 \mu \mathrm{m}(a)$ and $30 \mu \mathrm{m}(b)$

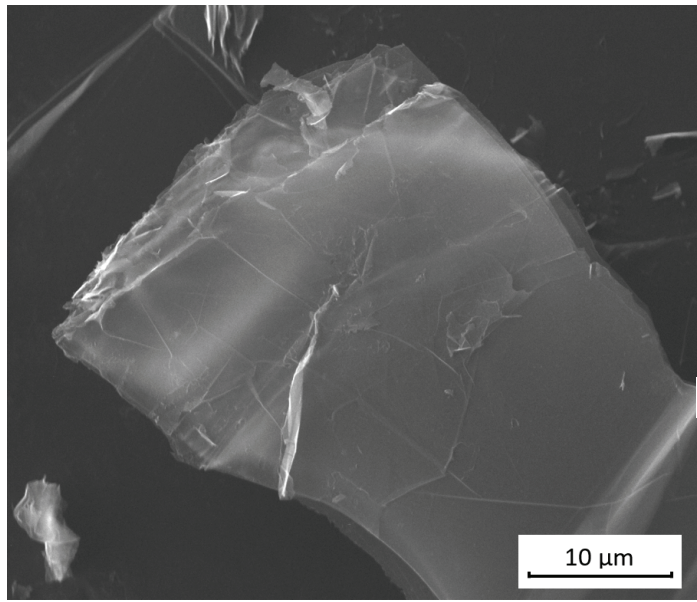

(a)

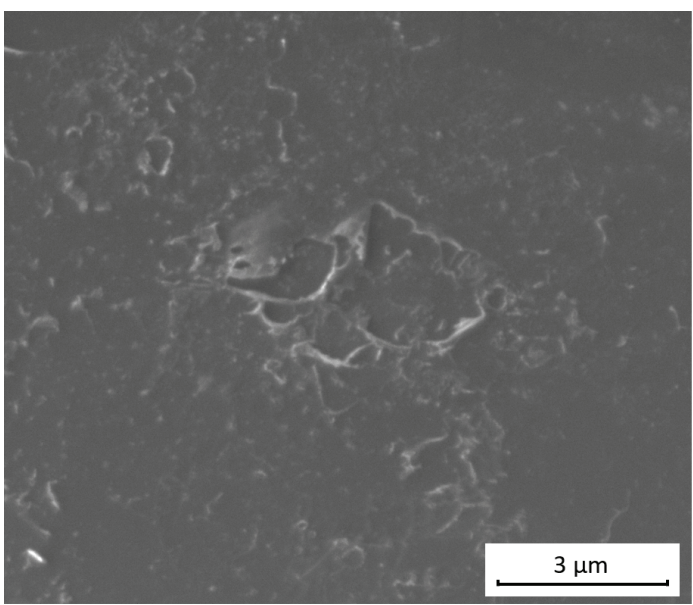

(b)

Fig. 4. SEM images: $a$ - packages of graphite layers; $b$-delamination of the upper graphite layer

Graphene sheets obtained by processing the glassy carbon surface using the ytterbium laser system have a fundamentally different shape (Fig. 5). Graphene sheets form crumples with a complex folded structure. Crumples with a characteristic size of about 1 micron were recorded.

The complex relief of the recorded surface of these structures did not allow direct measurement of graphene sheets thickness; however, the transverse dimension of the crumple bends was about $40 \mathrm{~nm}$. It is obvious that the crumple has a transverse dimension not less than twice the sheet thickness. In addition, it is necessary to take into account the presence of a certain bend radius. Thus, the thickness of the obtained graphene sheets can be estimated at the level of $15 \mathrm{~nm}$, which is similar to the results observed during laser processing of HOPG targets.

The formation of crumpled graphene can be explained by the destruction of the material surface. When laser radiation interacts with a carbon target, the initial carbon structures are destroyed (opened), deformed and cleaned, which determines the thickness of the obtained multilayer graphene.

The general picture of processing the glassy carbon surface by femtosecond laser radiation of the titanium-sapphire laser system under conditions of

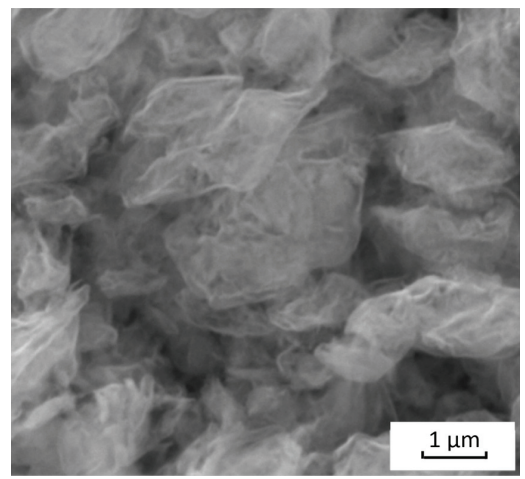

Fig. 5. SEM image of crumpled graphene on the glass carbon surface 
rapid cooling is rather complicated. In the ideal case, when the roughness of the sample surface is minimal and there are no foreign inclusions, the treated surface looks like a system of nanopeaks with practically the same height. Large irregularities (relative to the average size of the formed structures) distort the overall nature of the processing results.

Studying the images of the sample surface treated with femtosecond laser radiation obtained using a scanning electron microscope (SEM images) revealed the absence of melting traces within the exposure area. Obviously, the destruction of glassy carbon under laser radiation during the set experiments proceeds according to the scenario standard for carbon and materials based on it. In other words, sublimation occurs. The destruction nature of the irradiated samples explains the fact that the boundaries of these areas are not traced in the tracks of the glassy carbon surface treatment by a laser beam moving at a speed that implies overlapping the areas of individual pulses. Otherwise (during melting), the rolls of the solidified melt quite expressively outline the spots of individual laser pulses. In this case, the limits of individual pulses can theoretically be determined by the change in the level of the treated surface. However, the relatively low energy of femtosecond laser pulses determines the insignificant value of this change. In addition, the modified surface is a system of nanopeaks that have a scatter of heights. This additionally masks the range of action of the individual laser pulses.

Regions with both random and regular nanopeaks were recorded on the surface modified by laser radiation (Fig. 6). In the latter case, the nanopeaks form rows.

Figure 6 shows that nanopeaks in a region with a regular arrangement have a diameter of about $100 \mathrm{~nm}$. The distance between the rows (the period of the general structure) is about $100 \mathrm{~nm}$. The distance between the peaks in the row is also about $100 \mathrm{~nm}$.
It should be noted that there are two significant differences between the considered findings and the results of processing materials by ultrashort laser pulses in liquid media presented in the scientific literature. These differences can be explained only by a change in laser processing conditions due to the use of a cryogenic liquid (liquid nitrogen) as a buffer medium.

Firstly, the formation of periodic structures with characteristic dimensions multiple of the wavelength of the incident radiation and tending to a value of $100 \mathrm{~nm}$ was recorded when exposed to a large number of laser pulses. According to generalized data, the number of acting impulses should be $10^{3}$ [26]. In our case, the glassy carbon surface was treated with a laser beam moving over the target surface at a speed of $2.5 \mathrm{~cm} \cdot \mathrm{s}^{-1}$. In this case, there was $75 \%$ overlap of the laser action areas, as in previous experiments. Nevertheless, the formation of regular structures with a period of about $100 \mathrm{~nm}$ occurred.

Secondly, the currently obtained results of processing materials by ultrashort laser pulses showed an increase in the period of regular structures with an increase in the radiation energy density and determined the limit, at which the formation of periodic structures stops.

Relatively large structures that are clearly of an interference nature are superimposed on the general picture of the surface modified by femtosecond laser radiation in the form of the nanopeaks system. They look like circles diverging from a common center. A typical view of these structures is shown in Fig. 7. The central circle is pronounced. The contrast of subsequent circles decreases away from the center of the system. The average diameter of the described structures determined from the last distinguishable circle is about $24 \mu \mathrm{m}$.

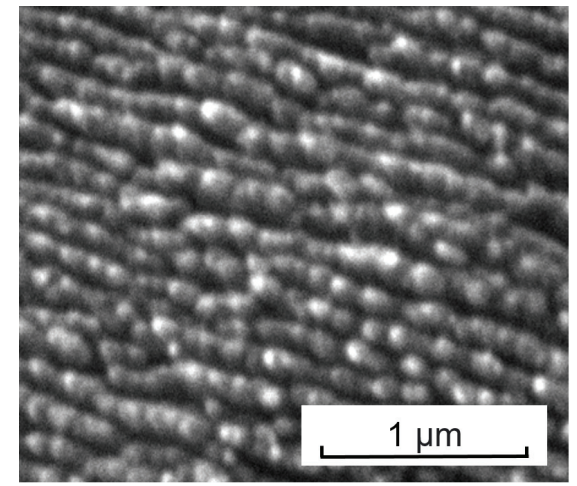

(a)

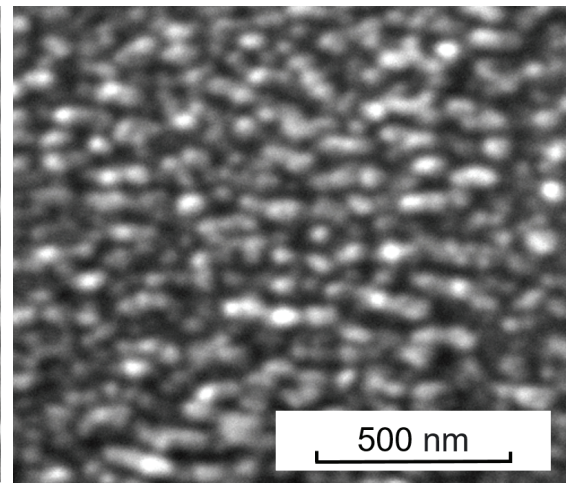

(b)

Fig. 6. SEM images of nanopeaks on the glass carbon surface:

$a$ - a region with a random arrangement of nanopeaks; $b$ - a region with a regular arrangement of nanopeaks 


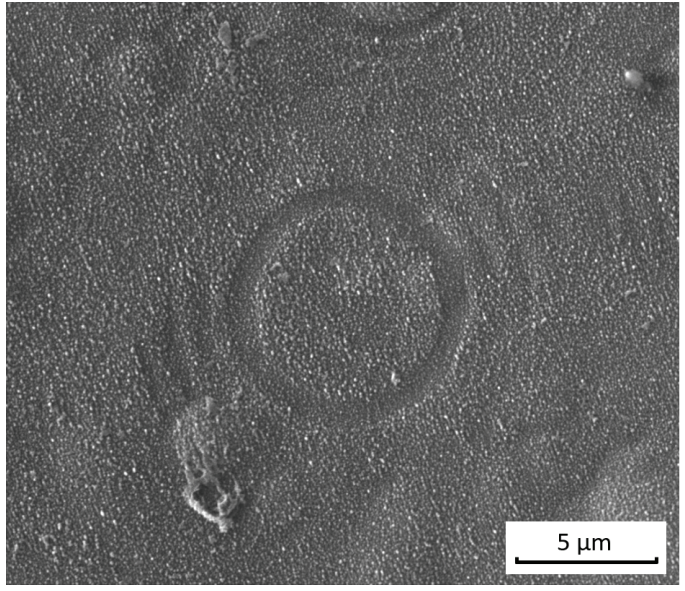

(a)

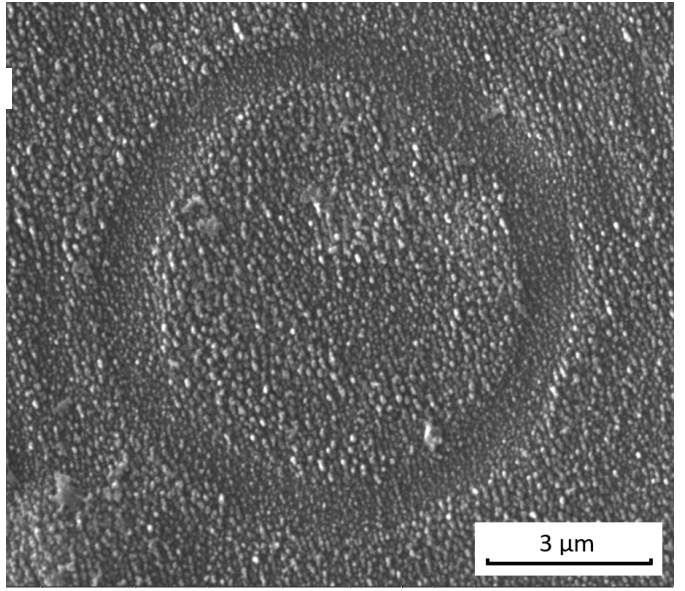

(b)

Fig. 7. SEM images of microstructure on the glass carbon surface after laser processing: $a$ - general view; $b$ - enlarged image

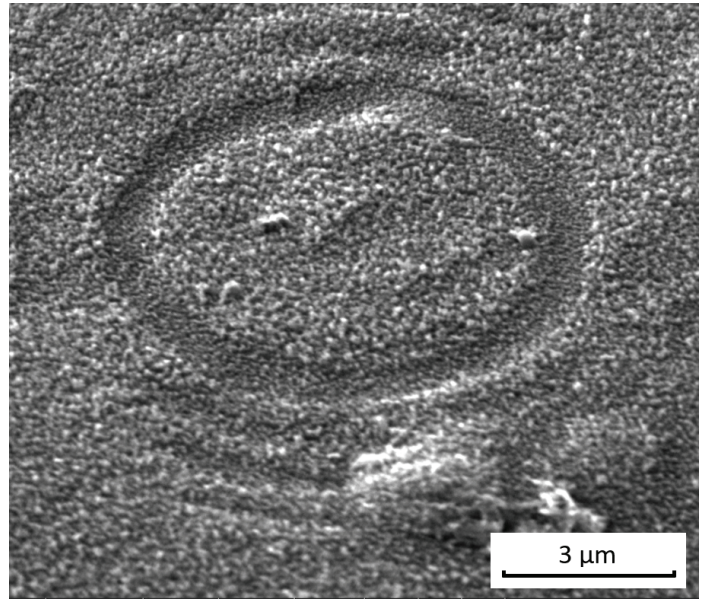

(a)

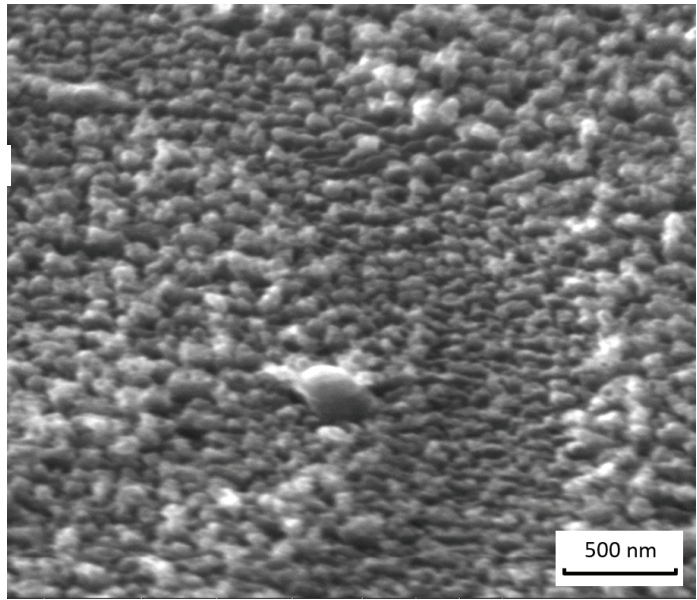

(b)

Fig. 8. SEM images of microstructure at an angle of $45^{\circ}$ to the glass carbon surface after laser processing: $a$ - general view; $b$ - enlarged image

The central region of the structures has an average diameter of about $7 \mu \mathrm{m}$. The first "dark" ring is about $800 \mathrm{~nm}$ wide. The period of subsequent structures is of comparable magnitude. Visually, the elements of the described structures have different brightness and can be conditionally divided into "light" and "dark". Obviously, the brightness of the elements is determined by their height, i.e. the "dark" areas correspond to the depressions. This conclusion is confirmed by SEM images taken at an angle of $45^{\circ}$ to the sample surface (Fig. 8). The glassy carbon surface modulated by microstructures is still an array of nanopeaks, both on protrusions and in depressions.

Comparing the results of processing HOPG and GC by femtosecond laser radiation in liquid nitrogen showed that the use of the first material is preferable for the purpose of obtaining as smooth and thin graphene sheets as possible. Obviously, in this case, the decisive role is played by the initial internal structure of the irradiated materials.
The thermal expansion of the graphite lattice is anisotropic, as are the values of the thermal and electrical conductivity of this material. The anisotropy for graphite is manifested the stronger, the higher the lattice ordering. The temperature coefficient of linear expansion in the direction of the basal planes is much lower than in the perpendicular direction, which contributes to the stratification of the structure during intense heating.

Cooling graphite to liquid nitrogen temperatures reduces the lattice vibrations of the initial graphite material and the interlayer distance decreases to $3.339 \AA$, while upon heating it increases to $3.465 \AA$ (at $1000^{\circ} \mathrm{C}$ ) [25]. This procedure is often used due to the availability of rapid cooling technologies appropriate boiling points and small sizes of nitrogen molecules ensuring its high fluidity. At low temperatures, the graphite lattice becomes less "plastic", which is likely to make it possible to destroy interplanar bonds with a smaller energy 
contribution to the places of local heating of nitrogen molecules diffused into the interplanar distance.

When ultrashort laser pulses interact with a graphite sample in liquid nitrogen, several variants of structural changes in the material can be distinguished. When the power of laser radiation is insufficient for the occurrence of laser ablation processes [27], the energy of photons is absorbed by the lattice of carbon and diffused nitrogen. Due to the resulting sharp increase in the vibrations of the lattice and nitrogen molecules, weak interplanar $\pi$-bonds are destroyed. Peeling and splitting off graphite layers occurs mainly on defects of the processed structure (cracks, chips, scratches, including dissimilar lattice defects in the form of gaps that facilitate the penetration of liquid nitrogen molecules). Accordingly, an increase in the number of nitrogen atoms in the material lattice promotes more intense delamination of graphene sheets.

Figure 9 shows the experimental result of graphene structures detachment on the HOPG surface in the crack region. In this case, it is clearly noticeable that the separation begins from the center of the crack according to the mechanism described above. On the SEM image with a high magnification, it can be seen that individual structures exfoliate and bend in the direction from the starting point of separation at the base, and in some places they also delaminate. The next step for graphene sheets is their separation from the original sample during ultrasonic treatment and the formation of a colloid with deposition on a solid substrate.

When the energy of laser radiation exceeds the ablation development threshold, the destruction of the graphite surface occurs in the area of laser action. As a result of laser ablation processes, a high-pressure region is formed on the walls of the formed cavity. The separation of the graphite structure into multilayer graphene with this mechanism occurs as a result of the reactive action of the ablation products.

The SEM images (Fig. 10) show the scanning area of the laser beam which leads to "stepwise" separation of graphene layers upon activation of the femtosecond laser ablation mode [27].

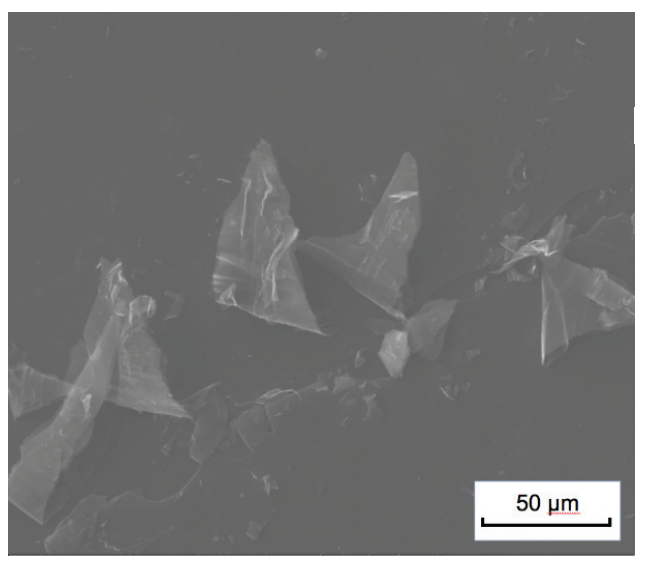

(a)

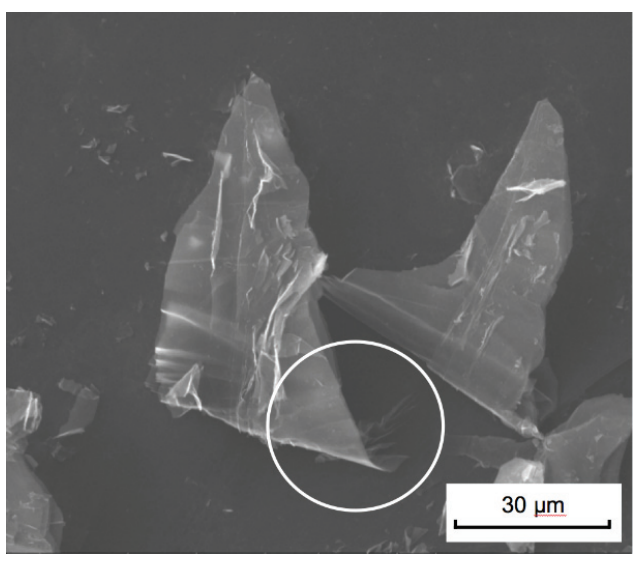

(b)

Fig. 9. SEM images of the edges of graphene sheets with different magnifications: $a-\times 1000 ; b-\times 2000$

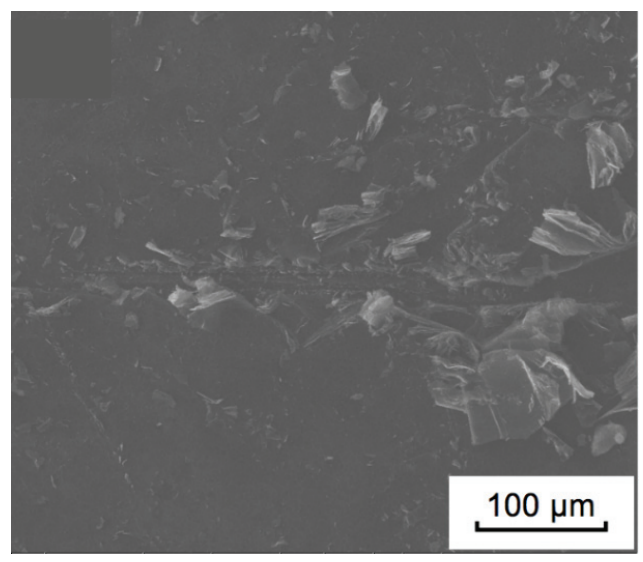

(a)

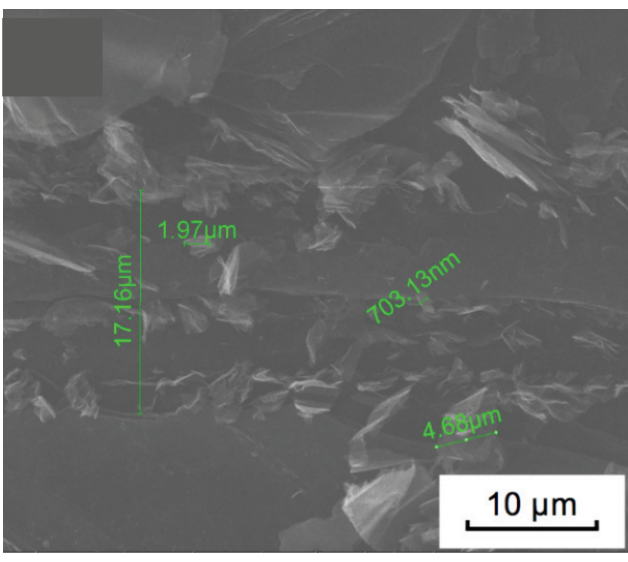

(b)

Fig. 10. SEM images of the laser processing area with different magnifications: $a-\times 500 ; b-\times 5000$ 
Thus, the general mechanism of graphene exfoliation under femtosecond laser irradiation in liquid nitrogen is the detachment of the target surface layers as a result of interplanar bonds disruption in carbon samples due to the expansion of intercalated nitrogen into the gas phase upon laser heating with simultaneous cooling in liquid nitrogen.

In terms of application purposes, we can talk about the development of electrical energy storage devices with increased capacity due to the use of crumpled graphene as a material for the electrode plates, which serves as a material that not only provides efficient transport for ion diffusion, but also has a significant specific surface area resistant to aggregation and a rigid structure [28-30], which allows maintaining this structure even after immersion in an electrolyte or ionic liquid solution.

As practice shows, it is difficult to achieve theoretical extremely high values of graphene specific surface area (fundamental for such applications). Re-stacking and agglomeration of graphene sheets leads to a strong decrease in the available surface for charge accumulation and a decrease in the gravimetric capacity [31-33]. The use of crumpled graphene as a basis is relevant for using energy storage devices in such schemes. Crumpled graphene can give superior capacitance values due to its high specific surface area, high electrical conductivity and resistance to graphitization compared to flat sheets.

The operation principle of the discussed supercapacitor design, i.e. the charge accumulation mechanism, is based on the formation of an electric double layer on the electrode surface due to the desorption of ions from the solution. Today this technology is promising for the development of new types of supercapacitors with the formation of an electric double layer on the surface of electrodes made of crumpled graphene.

Further development of our research will be associated with the electrophysical characteristics of various graphene structures, including the control of the band gap, regulation of the extremely high transport of charge carriers with a nonequilibrium state, and the features of the Hall effect. The possibility of obtaining highly transparent conductors allows to hope for their widespread use in thin-film devices of photonics and optoelectronics based on new physical principles (see, for example, [34]), including low-power displays, touch screens, LEDs, solar panel elements, etc.

This corresponds to the general direction of exploratory research and breakthrough technologies using the unique properties of graphene, which is currently one of the key and massive high-tech developments for various applications. It is enough to cite only the titles of works on this topic. For example, a graphene superconductor was obtained [35]; in this case, the superconductivity of graphene can be turned off [36]. A two-dimensional spin field-effect transistor based on graphene was constructed [37] and a superconducting transistor made of graphene was presented [38]. The "magic" superconductivity of bilayer graphene is explained by the interaction with phonons [39-42]. In this case, the motion of photons and electrons in graphene can be described by one law [43], and entanglement can arise in a superconductor [44]. Similar effects for three-layer graphene are possible even at high temperatures [45].

Progress in these fundamental areas should be associated with advances in such a field of fundamental and applied research as femtonanophotonics (see, for example, [46]). In fact, we are talking about the development of technologies based on new principles for controlling the functional properties of materials and creating the controlled characteristics of elements and systems on their basis in a given direction in the process of their creation when the medium is exposed to laser pulses with extremely short time parameters, as well as the formation of spatial topological nanostructures of different dimensions with the manifestation of macroscopic quantum effects. In this aspect, graphene-like structures represent a fundamentally new class of 4D technologies, in which domestic scientific and technical developments are competitive in the global landscape of science intensive technologies.

\section{Conclusion}

This work presents the developed method for laser-induced graphene separation in liquid nitrogen using an ytterbium femtosecond laser system. It also demonstrates the possibility of forming ordered structures on the surface of carbon samples using a titanium-sapphire laser system.

In the experiments, liquid nitrogen was used as a medium that helps to reduce the thermal effect of the plasma torch which is formed over the area of femtosecond laser radiation above the material surface during processing in air. The use of liquid nitrogen makes it possible to neutralize a number of negative features of air processing.

Thus, it was found that graphene formation under the action of femtosecond laser radiation on carbon samples in liquid nitrogen occurs according to 
the following two-stage mechanism: (i) breaking weak interplanar $\pi$-bonds due to heating of intercalated nitrogen into the graphite lattice; (ii) detachment of the target surface layers due to the formation of a high-pressure area in the walls of the laser cavity.

\section{Funding}

This study did not receive external funding.

\section{Conflict of interests}

The authors declare no conflict of interest.

\section{References}

1. Eletskii AV, Iskandarova IM, Knizhnik AA, Krasikov DN. Graphene: fabrication methods and thermophysical properties. Physics-Uspekhi. 2011;54(3):227258. DOI:10.3367/UFNe.0181.201103a.0233

2. Alekseenko AG. Graphene. Moscow: BINOM. Knowledge Laboratory; 2014. p.177. (In Russ.)

3. Tkachev SV, Buslaeva EYu, Gubin SP. Graphene: a novel carbon nanomaterial. Inorganic Materials. 2011;47(1):5-14. DOI:10.1134/S0020168511010134

4. Grayfer ED, Makotchenko VG, Nazarov AS, Fedorov VE, Kim SJ. Graphene: chemical approaches to the synthesis and modification. Russian Chemical Reviews. 2011;80(8):751-770. DOI:10.1070/RC2011v080n 08ABEH00418

5. Stankovich S, Dikin DA, Dommett GHB, Kohlhaas KM, Zimney EJ, Stach EA, Piner RD, Nguyen ST, Ruoff RS. Graphene-based composite materials. Nature. 2006;442(7100):282-286. DOI:10.1038/ nature 04969

6. Razumov VF. Graphene - a new breakthrough in the field of nanotechnology. Rossijskie Nanotexnologii $=$ Nanotechnologies in Russia. 2010;5(11-12):17-22. (In Russ.)

7. Hua-Qiang W, Chang-Yang L, Hong-Ming L, $\mathrm{He}$ Q. Graphene applications in electronic and optoelectronic devices and circuits. Chinese Physics $B$. 2013;22(9):098106(1-11). DOI:10.1088/1674-1056/22/9/ 098106

8. Avouris P, Xia F. Graphene applications in electronics and photonics. MRS Bulletin. 2012;37(12):1225-1234. DOI:10.1557/mrs.2012.206

9. Yudintsev V. Graphene. Nanoelectronics on the wings of the wind develops in strength. Elektronika: Nauka, tekhnologiya, biznes. 2009;(6):82-89. (In Russ.)

10. Ivanovskii AL. Graphene-based and graphenelike materials. Russian Chemical Reviews. 2012;81(7):571605. DOI:10.1070/RC2012v081n07ABEH004302

11. Shahil KMF, Balandin AA. Thermal properties of graphene and multilayer graphene: Applications in thermal interface materials. Solid State Communications. 2012;152(15):1331-1340. DOI:10.1016/j.ssc.2012.04.034
12. Galashev AE, Rakhmanova OR. Mechanical and thermal stability of graphene and graphene-based materials. Physics-Uspekhi. 2014;57(10):970-989. DOI: 10.3367/UFNr.0184.201410c.1045

13. Yan Z, Nika DL, Balandin AA. Thermal properties of graphene and few-layer graphene: applications in electronics. IET Circuits, Devices \& Systems. 2015;9(1):4-12. DOI:10.1049/iet-cds.2014.0093

14. Stoller MD, Park S, Zhu Y, An J, Ruoff RS. Graphene-based ultracapacitors. Nano Letters. 2008;8(10):3498-3502. DOI:10.1021/nl802558y

15. Raccichini R, Varzi A, Passerini S, Scrosati B. The role of graphene for electrochemical energy storage. Nature Materials. 2015;14(3):271-279. DOI:10.1038/ nmat4170

16. Novoselov KS, Jiang D, Schedin F, Booth TJ, Khotkevich VV, Morozov SV, Geim AK. Twodimensional atomic crystals. Proceedings of the National Academy of Sciences. 2005;102(30):10451-10453. DOI:10.1073/pnas.0502848102

17. Ionin AA, Kudryashov SI, Samokhin AA. Material surface ablation produced by ultrashort laser pulses. Physics-Uspekhi. 2017;60(2):149-160. DOI:10.3367/ UFNe.2016.09.037974

18. Bulgakov AV, Bulgakova NM, Burakov IM. Synthesis of nanoscale materials under the influence of powerful energy flows on matter. Novosibirsk: Institute of Thermophysics SB RAS; 2009. 461 p. (In Russ.)

19. Abramov DV, Arakelian SM, Galkin AF, Kvacheva LD, Klimovskii II, Kononov MA, Mikhalitsyn LA, Kucherik AO, Prokoshev VG, Savranskii VV. Melting of carbon heated by focused laser radiation in air at atmospheric pressure and temperature below $4000 \mathrm{~K}$. JETP Letters. 2006;84(5):258-261. DOI:10.1134/ S0021364006170061.

20. Abramov DV, Gerke MN, Kucherik AO, Kutrovskaya SV, Prokoshev VG, Arakelyan SM. Formation of nanostructures at the glass-carbon surface exposed to laser radiation. Quantum Electronics. 2007;37(11):1051-1054.

DOI:10.1070/QE2007v037 n11ABEH013560.

21. Abramov DV, Arakelian SM, Kochuev DA, Makov S, Prokoshev VG, Khorkov KS. Interaction of femtosecond laser radiation with carbon materials: exfoliation of graphene structures and synthesis of lowdimensional carbon structures. Nanosystems: Physics, Chemistry, Mathematics. 2016;7(1):220-225. DOI:10.17586/ 2220-8054-2016-7-1-220-225

22. Chkalov RV, Khorkov KS, Kochuev DA, Davydov N, Prokoshev VG, Kostrov V. Computerized laser complex for monitoring and controlling of the precision micromachining processes. Proceedings of the International Conferences on WWW/INTERNET 2018 and APPLIED COMPUTING 2018. 21-23 October 2018, Budapest. Hungary: IADIS Press; 2018. p. 395-399.

23. Abramov DV, Arakelian SM, Kochuev DA, Makov SA, Prokoshev VG, Khorkov KS. Graphene production method. Russian Federation patent. 2,572,325. 10 January 2016. 
24. Khorkov KS, Kochuev DA, Ilin VA, Prokoshev VG, Arakelian SM. Laser synthesis of graphene in liquid nitrogen. IOP Conference Series: Materials Science and Engineering. 2019;525:012052(1-7). DOI:10.1088/ 1757-899X/525/1/012052

25. Mortazavi SZ, Parvin P, Reyhani A. Fabrication of graphene based on Q-switched Nd: YAG laser ablation of graphite target in liquid nitrogen. Laser Physics Letters. 2012;9(7):547-552. DOI:10.7452/LAPL.201210033

26. Makin VS, Makin RS. Nonlinear interaction of linearly polarized laser radiation with condensed media and overcoming the diffraction limit. Optics and Spectroscopy. 2012;112(2):162-167. DOI:10.1134/ S0030400X12020208

27. Khorkov KS, Kochuev DA, Ilin VA, Chkalov RV, Prokoshev VG, Arakelian SM. Mechanisms of graphene exfoliation under the action of femtosecond laser radiation in liquid nitrogen. Journal of Physics: Conference Series. 2018;951(1):012014. DOI:10.1088/1742-6596/951/1/012014

28. El Rouby, Waleed MA. Crumpled graphene: preparation and applications. RSC Advances. 2015;5(82):66767-66796. DOI:10.1039/C5RA10289H

29. Zang J, Ryu S, Pugno N, Wang Q, Tu Q, Buehler MJ, Zhao X. Multifunctionality and control of the crumpling and unfolding of large-area graphene. Nature Materials. 2013;12(4):321-325. DOI:10.1038/nmat3542

30. Cranford SW, Buehler MJ. Packing efficiency and accessible surface area of crumpled graphene. Physical Review B. 2011;84(20):205451(1-7). DOI:10.1103/ PhysRevB.84.205451

31. Liu C, Yu Z, Neff D, Zhamu A, Jang BZ. Graphene-based supercapacitor with an ultrahigh energy density. Nano Letters. 2010;10(12):4863-4868. DOI:10.1021/ nl102661q

32. Stoller MD, Park S, Zhu Y, An J, Ruoff RS. Graphene-based ultracapacitors. Nano letters. 2008;8(10):3498-3502. DOI:10.1021/nl802558y

33. Raccichini R, Varzi A, Passerini S, Scrosati B. The role of graphene for electrochemical energy storage. Nature Materials. 2015;14(3):271-279. DOI:10.1038/ nmat4170

34. Arakelian SM, Kucherik AO, Khudaberganov TA, Bukharov DN, Istratov AV, Khorkov KS, Osipov AV, Butkovskiy OYa. Nanophysics in laserinduced cluster systems: topological quantum states in electrical conductivity and features of optical spectratheory and experiment for dimensional effects. Optical and Quantum Electronics. 2020;52:202(1-21). DOI:10.1007/ s11082-020-02308-6

35. Di Bernardo A, Millo O, Barbone M, Alpern H, Kalcheim Y, Sassi U, Ott AK, De Fazio D, Yoon D, Amado M, Ferrari AC, Linder J, Robinson JWA. P-wave triggered superconductivity in single-layer graphene on an electron-doped oxide superconductor. Nature Communication. 2017;8:14024(1-9). DOI:10.1038/ ncomms 14024
36. Bistritzer R, MacDonald AH. Moiré bands in twisted double-layer graphene. Proceedings of the National Academy of Sciences. 2011;108(30):12233-12237. DOI:10.1073/pnas.1108174108

37. Ghiasi TS, Kaverzin AA, Blah PJ, VanWees BJ. Charge-to-spin conversion by the Rashba-Edelstein effect in two-dimensional Van der Waals heterostructures up to room temperature. Nano Letters. 2019;19(9):5959-5966. DOI:10.1021/acs.nanolett.9b01611

38. Chen G, Sharpe AL, Gallagher P, Rosen IT, Fox EJ, Jiang L, Lyu B, Li H, Watanabe K, Taniguchi T, Jung J, Shi Z, Goldhaber-Gordon D, Zhang Y, Wang F. Signatures of tunable superconductivity in a trilayer graphene moiré superlattice. Nature. 2019;572:215-219. DOI:10.1038/s41586-019-1393-y

39. Cao Y, Fatemi V, Fang S, Watanabe K, Taniguchi T, Kaxiras E, Jarillo-Herrero P. Unconventional superconductivity in magic-angle graphene superlattices. Nature. 2018;556(7699):43-50. DOI:10.1038/nature26160

40. Cao Y, Chowdhury D, Rodan-Legrain D, RubiesBigorda O, Watanabe K, Taniguchi T, Todadri S, JarilloHerrero P. Strange metal in magic-angle graphene with near Planckian dissipation. Physical Review Letters. 2020;124(7):076801(1-7). DOI:10.1103/PhysRevLett. 124.076801

41. Wu F, MacDonald AH, Martin I. Theory of phonon-mediated superconductivity in twisted bilayer graphene. Physical Review Letters. 2018;121(25):257001(1-6). DOI:10.1103/PhysRevLett. 121.257001

42. Kerelsky A, McGilly LJ, Kennes DM, Xian L, Yankowitz M, Chen S, Watanabe K, Taniguchi T, Hone J, Dean C, Rubio A, Pasupathy AN. Maximized electron interactions at the magic angle in twisted bilayer graphene. Nature. 2019;572(7767):95-100. DOI:10.1038/s41586019-1431-9

43. Whittaker CE, Dowling T, Nalitov AV, Yulin AV, Royall B, Clarke E, Skolnick MS, Shelykh IA, Krizhanovskii DN. Optical analogue of Dresselhaus spinorbit interaction in photonic graphene. Nature Photonics. 2021;15(3):193-196. DOI:10.1038/s41566-020-00729-Z

44. Tan ZB, Laitinen A, Kirsanov NS, Galda A, Vinokur VM, Haque M, Savin A, Golubev DS, Lesovik GB, Hakonen PJ. Thermoelectric current in a graphene Cooper pair splitter. Nature Communications. 2021;12(1):138(1-7). DOI: $10.1038 / \mathrm{s} 41467-020-20476-7$

45. Hao Z, Zimmerman AM, Ledwith P, Khalaf E, Najafabadi DH, Watanabe K, Taniguchi T, Vishwanath A, Kim P. Electric field-tunable superconductivity in alternating-twist magic-angle trilayer graphene. Science. 2021;371(6534):1133-1138. DOI:10.1126/science.abg0399

46. Arakelian SM, Kucherik AO, Prokoshev VG, Rau VG, Sergeev AG. Introduction to femtonanophotonics. Fundamentals and laser methods for controlled production and diagnostics of nanostructured materials. Moscow: Logos; 2015. 744 p. (In Russ.) 


\section{Информация об авторах / Information about the authors}

Хорьков Кирилл Сергеевич, кандидат физикоматематических наук, директор института прикладной математики, физики и информатики, Владимирский государственный университет им. А.Г. и Н.Г. Столетовых, Владимир, Россия; ORCID 0000-0002-5402-0846; e-mail: khorkov@vlsu.ru

Прокошев Валерий Григорьевич, доктор физикоматематических наук, профессор, профессор кафедры физики и прикладной математики, Владимирский государственный университет им. А.Г. и Н.Г. Столетовых, Владимир, Россия; Researcher ID N-71302019; e-mail: prokoshev_vg@vlsu.ru

Аракелян Сергей Мартиросович, доктор физикоматематических наук, профессор, заведующий кафедрой физики и прикладной математики, Владимирский государственный университет им. А.Г. и Н.Г. Столетовых, Владимир, Россия; ORCID 0000-0003-1692-7356; e-mail: arak@vlsu.ru
Kirill S. Khorkov, Cand. Sc. (Physical and Mathematical), Director of the Institute of Applied Mathematics, Physics and Computer Science, Vladimir State University, Vladimir, Russia; ORCID 0000-00025402-0846; e-mail: khorkov@vlsu.ru

Valery G. Prokoshev, D. Sc. (Physical and Mathematical), Professor, Professor of the Department of Physics and Applied Mathematics, Vladimir State University, Vladimir, Russia; Researcher ID N-71302019; e-mail: prokoshev_vg@vlsu.ru

Sergei M. Arakelian, D. Sc. (Physical and Mathematical), Professor, Head of the Department of Physics and Applied Mathematics, Vladimir State University, Vladimir, Russia; ORCID 0000-0003-16927356; e-mail: arak@vlsu.ru 